\title{
SUPPRESSION OF VERTICAL VIBRATION IN RAILWAY VEHICLE CARBODIES THROUGH CONTROL OF DAMPING FORCE IN PRIMARY SUSPENSION: PRESENTATION OF RESULTS FROM RUNNING TESTS WITH METER-GAUGE CAR ON A SECONDARY LINE
}

\author{
YOSHIKI SUGAHARA \& TAKASHI KOJIMA \\ Running Gear Laboratory, Railway Technical Research Institute, Japan
}

\begin{abstract}
To improve vertical ride comfort in railway vehicles, the suppression of vertical bending-mode vibration and rigid-body-mode vibration in the carbody is essential. Primary suspension damping control systems, designed to reduce bending mode vibrations in carbodies for high-speed trains, have been proposed in the past. These systems consist of variable vertical dampers affixed to the primary suspension, accelerometers attached to the bogie frames, and a controller. Results from vehicle running tests carried out on a number of Shinkansen lines demonstrated that these systems reduced the power spectral density (PSD) peak value of vertical carbody vibration accelerations in the first-bending-mode by 80 per cent compared to when the system was not used. This paper reports on the application of this system to a meter-gauged vehicle. Vehicle running tests were carried out on a secondary meter-gauge line at moderately high running speeds (about $100 \mathrm{~km} / \mathrm{h}$ or lower). Test results showed that the system reduced the PSD peak of vertical vibration accelerations stemming from bending-mode vibrations of the carbody by almost 90 per cent thanks to an LQG controller tuned for reducing bending-mode vibrations. When vehicles run at low speed (about $60 \mathrm{~km} / \mathrm{h}$ ) on secondary lines, the rigid-body-mode vibrations of the carbody in the $1-2 \mathrm{~Hz}$ frequency range tend to increase from time to time. The system was therefore also applied to reduce these vibrations. Results from vehicle running tests applying the LQG controller that had been re-tuned for reducing rigid-body-mode vibrations, showed that the PSD peak in vibration accelerations at $1.2 \mathrm{~Hz}$ was reduced by half.

Keywords: railway vehicle, semi-active suspension, vibration control, primary suspension, variable damper.
\end{abstract}

\section{INTRODUCTION}

Active or semi-active suspension systems (hereinafter collectively called "vibration control systems") are known to be highly effective in reducing carbody vibrations, and for improving ride comfort for passengers [1], to the extent that now, in Japan, almost all Shinkansen vehicles and some express train vehicles have been equipped with lateral vibration control systems [2], [3]. In addition to this, a vertical vibration control system using variable secondary vertical dampers was developed by the authors of this paper [4], [5]. This second system is effective in reducing vertical rigid-body-mode vibrations and has been adopted on some sightseeing trains and luxury trains which run on both main lines and secondary lines [6].

The primary suspension damping control system, which was previously proposed by one of the authors [7], is a similar type of vibration control system and is designed to reduce vertical bending-mode carbody vibrations primarily in high-speed trains for the following reason: the natural frequency of this vibration is generally close to the frequency bandwidth which can be felt by passengers sensitive to vertical vibrations; therefore, the suppression of this vibration is essential for improving vertical ride comfort on high-speed trains. 
The system consists of affixing variable vertical dampers to the primary suspension, attaching accelerometers to the bogie frames, and adding a controller. The results of vehicle running tests carried out on a number of Shinkansen lines demonstrated that the system reduced the power spectral density (PSD) peak value in vertical vibration accelerations in the first-bending-mode by 80 per cent compared to when the system was not used [7], [8]. The system, however, has never been applied to vehicles running on secondary lines with slightly lower speeds (vehicle running speeds of $60-100 \mathrm{~km} / \mathrm{h}$ ).

This study therefore examines the system's application to meter-gauge vehicles running on secondary lines. This paper reports on the results of vehicle running tests that were performed and confirms that the system can reduce vertical carbody vibrations even in vehicles running on secondary lines. The system was also tested to try to reduce vertical rigidbody-mode carbody vibrations, for which the results are also reported.

\section{STRUCTURE OF THE PRIMARY SUSPENSION DAMPING CONTROL SYSTEM}

The primary suspension damping control, that was previously proposed, suppresses bendingmode carbody vibrations through the control of the damping force in the primary suspension of vehicles in the following way: the vertical vibration of the bogie frame, which is the major source of carbody vibrations, is suppressed by controlling the damping force in the primary suspension of a vehicle, which, in turn, suppresses carbody vibrations.

\subsection{Basic architecture}

Fig. 1 shows the overall structure of the primary suspension damping control system which was developed. Variable primary vertical dampers, used for damping force control, are mounted parallel to the primary (coil) springs. Each car is equipped with eight dampers, a controller, and four accelerometers [9].

The controller calculates the desired damping force required to suppress the vertical vibration acceleration of the carbody from acceleration of the bogie frames and supplies a command current to the dampers.

\subsection{Variable primary vertical damper}

Fig. 2(a) shows the variable primary vertical damper. This damper was designed for Shinkansen bogies however, therefore an attempt was made in this study to apply it to the bogie on a meter-gauge car. The basic specifications of this variable damper are as follows: damper installation length of $269 \mathrm{~mm}$, maximum damping force of $9.8 \mathrm{kN}$ (for a piston

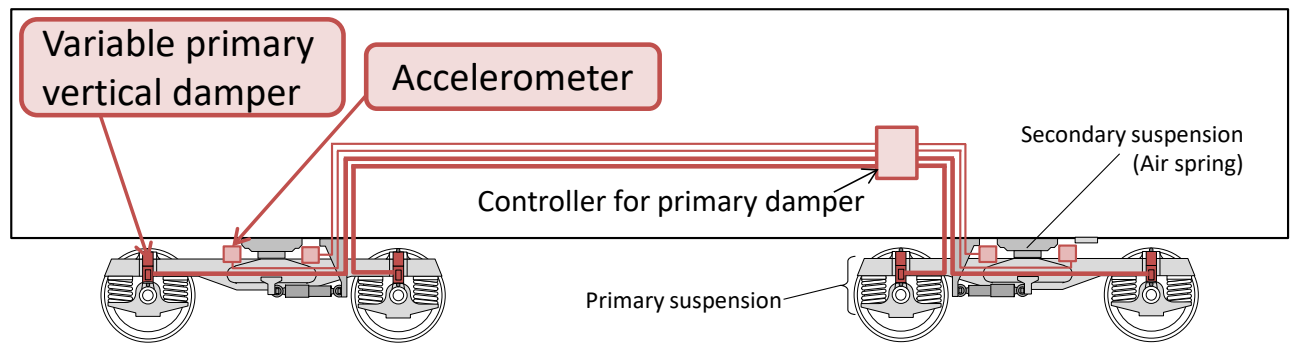

Figure 1: Primary suspension damping control system. 


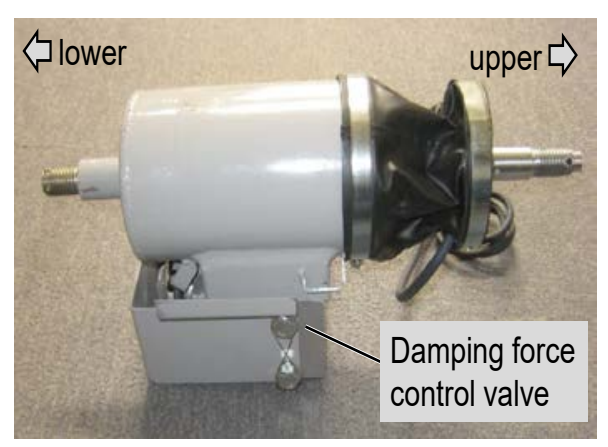

(a)

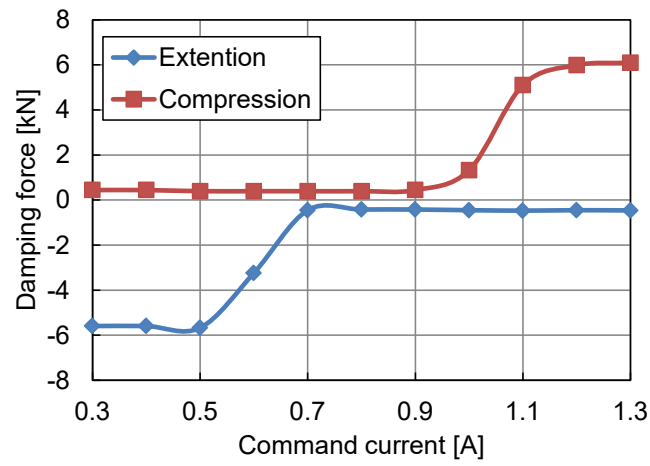

(b)

Figure 2: Variable primary vertical damper and its damping force characteristics. (a) Appearance; (b) Damping force characteristics.

speed of $0.6 \mathrm{~m} / \mathrm{s}$ ). This means that the damping control system can be fitted instead of the other primary vertical dampers without modifying the vehicle.

A reverse proportional solenoid control relief valve is used in the damping force control of this damper. Fig. 2(b) shows the command current-damping force characteristics of the variable primary vertical damper in the extension and compression directions at a fixed piston speed. This damper generates a damping force during its extension (denoted as "Extension" in the figure) from a small command current (approximately $0.3 \mathrm{~A}$ ), which falls to a minimum during the compression phased (indicated as "Compression" in the figure). When the command current is increased to approximately $1.3 \mathrm{~A}$, the opposite behaviour is observed. With an intermediate command current (approximately $0.8 \mathrm{~A}$ ), only a small damping force is generated during extension or compression. Thus, the direction and amplitude of the damping force generated by the variable primary vertical damper can be controlled by the command current alone, eliminating the need to consider piston stroke velocity of the damper in order to control the damping force. It is therefore possible to control the damper without measuring its displacement. When no power is being supplied to the control valves, the damper operates as passive damper confirming that the fail-safe function is achieved.

\subsection{Accelerometers}

The accelerometers for detecting vertical vibrations in each bogie frame are shown in Fig. 3(a). In the tests however, because of the need to control the bouncing and pitching modes of the bogie frames to obtain the best possible vibration reduction performance, the accelerometers were installed as shown in Fig. 3(b). N.B. Two accelerometers attached to the bogie frame directly above journal boxes (shown in blue in Fig. 3(b) were only used for pitching mode control. This is because, given constraints in the test set up, the red-coloured accelerometers (shown in Fig. 3(b)) could not be located immediately on the bogie frame centreline as shown in the figure. 


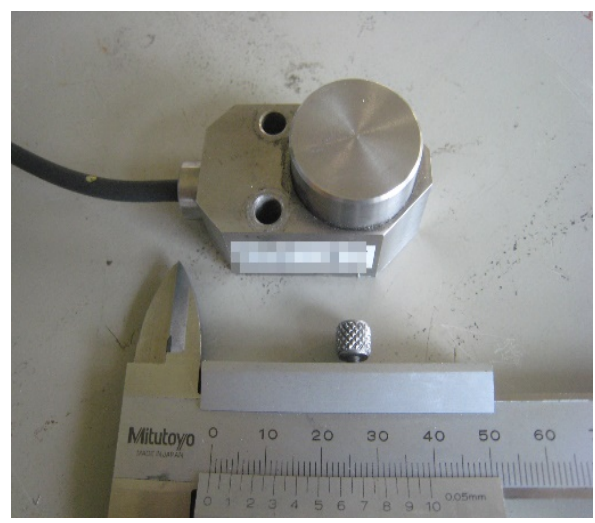

(a)

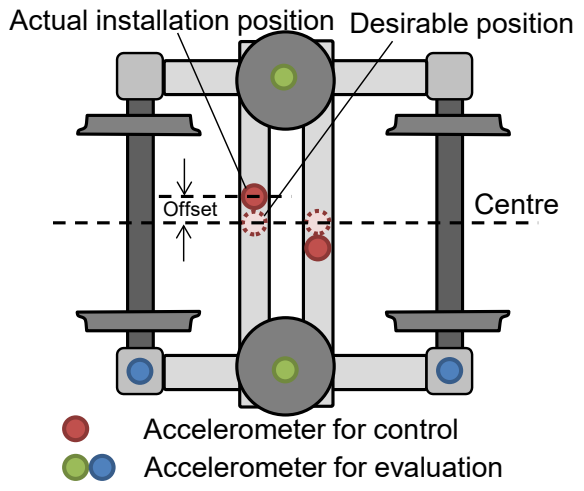

(b)

Figure 3: Accelerometer and its placement for primary damping control. (a) Appearance; (b) Placement of accelerometers on bogie frame.

\subsection{Control algorithm}

Although various control laws can be applied for controlling primary vertical dampers, this paper describes the case where the Sky-hook control law [10], and the Linear-QuadraticGaussian (LQG) control law [11] was applied.

Fig. 4(a) shows a block diagram of the controller when the Sky-hook control law is used for controlling primary vertical dampers. The vertical vibration acceleration of the bogie frame is separated into bouncing and pitching modes, and each component is integrated through a filter to obtain the vertical vibration velocity for each vibration mode. Vibrations in the bogie frame are reduced when the damper generates a force proportional to the velocity in the direction opposite the velocity. In this control method, the vibration of the bogie frame is reduced without considering the vibration mode of the carbody; therefore, in principle, it is not necessary to know the vibration characteristics of the vehicle; however, this means that this method cannot be used to control the dampers in consideration of the vibration characteristics of the carbody.

The LQG control law is one among a series of "modern control theories" based on stochastic optimal control. Fig. 4(b) shows a block diagram of the controller when the LQG control law is used for controlling primary vertical dampers. On the basis of the predetermined numerical model (i.e. the nominal model) of a vehicle, the values for the state of the vehicle model are estimated from the measured vertical vibration accelerations of the bogie frames using a Kalman filter. Optimal control is then performed using the estimated state values. This method enables vibration control in consideration of the vibration mode of the carbody, making it possible to selectively suppress the first-bending-mode vibrations of the carbody.

Only the bouncing of the bogie frame was controlled by the LQG controller using a 5DOF vehicle model; the pitching of the bogie frame was controlled using sky-hook control. This means a reduction in the dimensions of the LQG controller, allowing a reduction in the calculation load on the control system. 


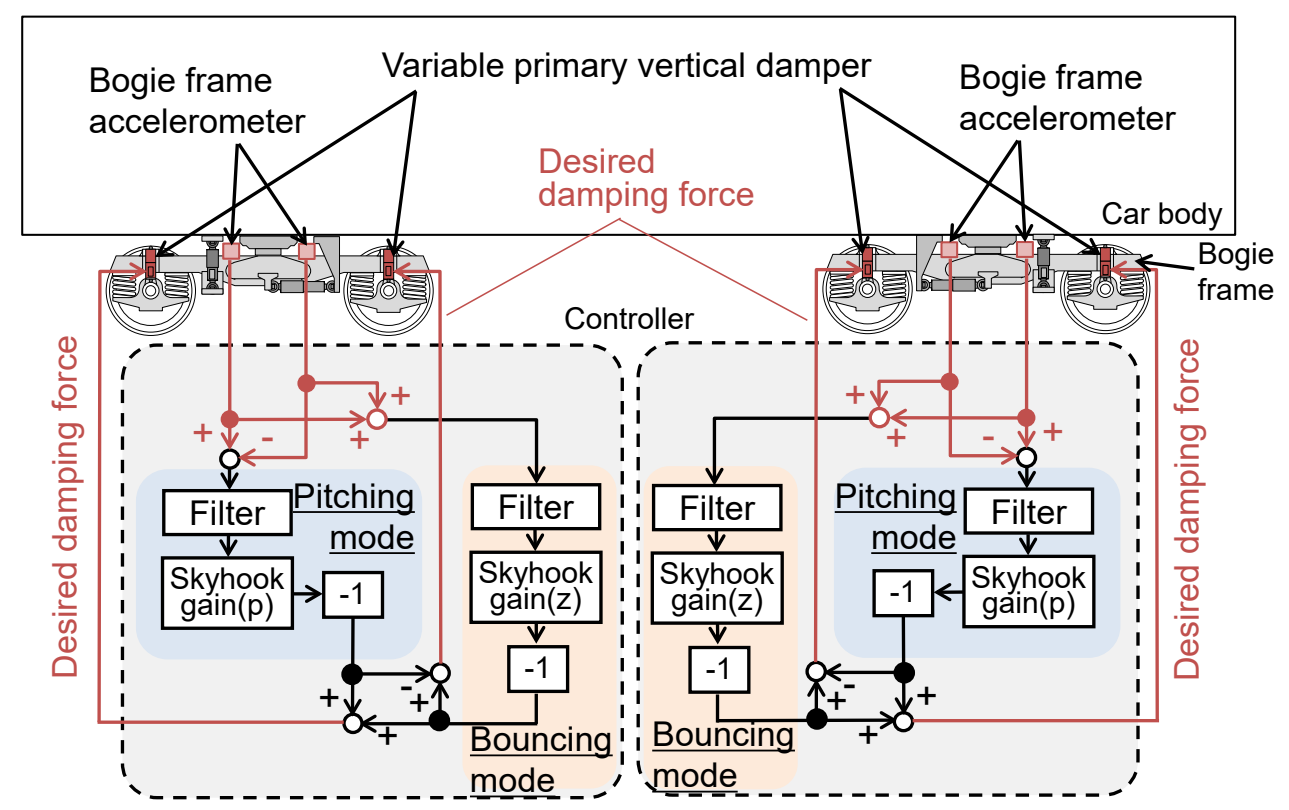

(a)

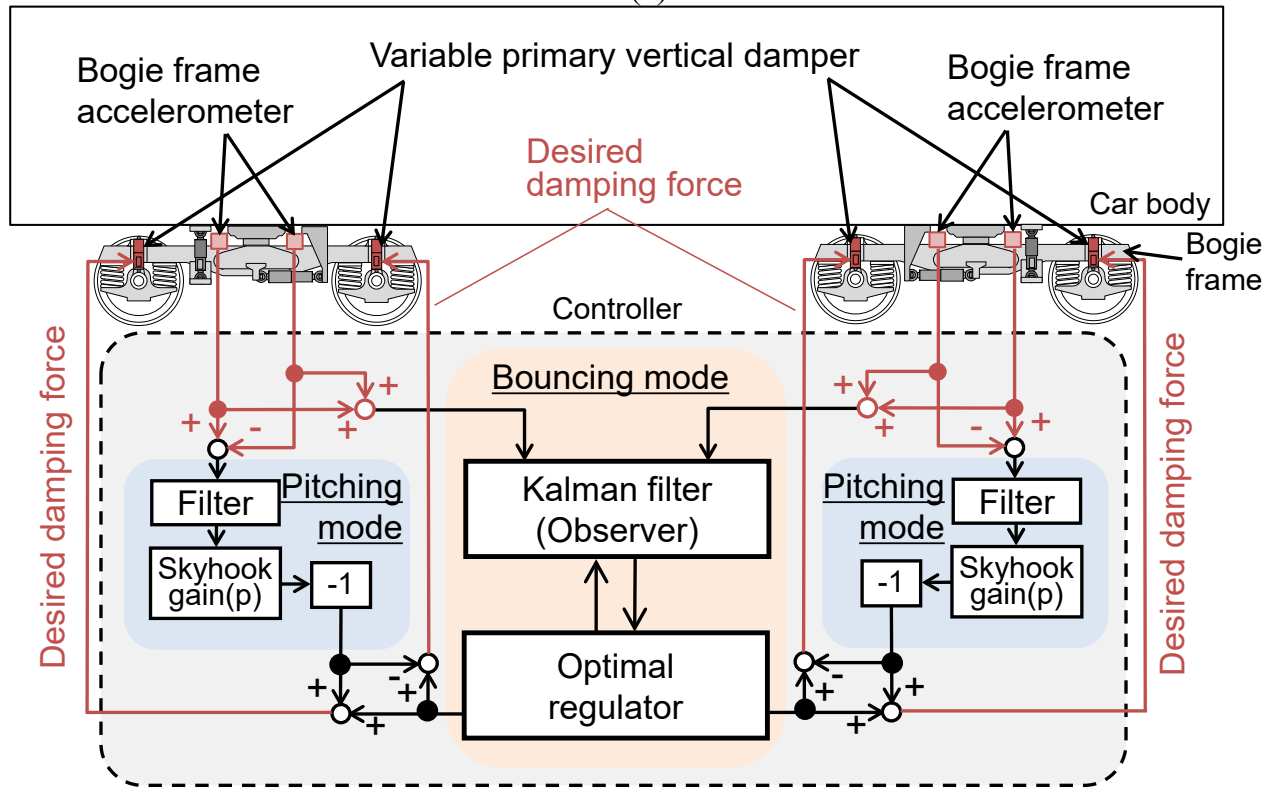

(b)

Figure 4: Block diagram for controlling primary vertical dampers. (a) Sky-hook control; (b) LQG control. 


\section{PERFORMANCE DEMONSTRATION OF THE SYSTEM USING ACTUAL VEHICLES IN RUNNING TESTS}

\subsection{Test condition}

Vehicle running tests on a secondary line were carried out in cooperation with the Kyushu Railway Company. As track maintenance criteria in the running test section were not very high, there was a tendency for $1-2 \mathrm{~Hz}$ carbody vibrations in rigid-body-modes to increase. The test vehicle was a meter-gauge car of $20 \mathrm{~m}$ in length, a distance between bogie centres of $14.15 \mathrm{~m}$, and a sprung mass of approximately $27,600 \mathrm{~kg}$.

\subsection{Test results for vertical vibration reduction}

\subsubsection{Reduction of bending mode carbody vibrations}

The sky-hook control and LQG control, were both adjusted to reduce first-bending-mode carbody vibrations and tested in vehicle running tests.

Fig. 5 shows the power spectral density (PSD) of the vertical vibration acceleration for the test section (running speed of $100 \mathrm{~km} / \mathrm{h}$ ) where bending-mode carbody vibrations were particularly marked. An acceleration PSD peak due to bending-mode vibrations was observed at approximately $11 \mathrm{~Hz}$ both directly above the rear bogie centre (Fig. 5(a)) and in the centre of the carbody (Fig. 5(b)). These vibrations need to be supressed, because the frequency $(11 \mathrm{~Hz})$ is close to the frequency bandwidth which can be felt by passenger's sensitive to vertical vibrations (4 to $8 \mathrm{~Hz}$ ) [12].

Applying the sky-hook control ("Sky-hook (BM)" in Fig. 5), vibrations with a frequency of around $11 \mathrm{~Hz}$ were slightly suppressed compared with cases "without control". In contrast, applying LQG control ("LQG (BM)" in Fig. 5), the PSD peak around $11 \mathrm{~Hz}$ was markedly reduced especially around the floor of the carbody centre, without adversely affecting the performance of vibration isolation in other frequency bands.

\subsubsection{Reduction of rigid-body-mode carbody vibrations}

Secondary line tracks in particular sometimes have relatively significant irregularities because maintenance criteria for secondary lines are lower than for mainlines. As a result, rigid-body-mode vibrations, and in particular those in the $1-2 \mathrm{~Hz}$ frequency range, tend to increase as shown in Fig. 5, which may result in reduced ride comfort.

Secondary suspension damping control systems using variable vertical dampers are known to be effective in suppressing this type of vibration. This study examines an attempt to reduce - even by a small margin - rigid-body-mode vibrations using a primary suspension damping control system. The sky-hook control and LQG control, which were both adjusted to reduce rigid-body-mode carbody vibrations (by tuning the weighting matrix used on designing LQG controllers), were tested in running tests.

Fig. 6 shows the PSD of the vertical carbody vibration acceleration for the test section on the secondary line used in the tests (running speed of $60 \mathrm{~km} / \mathrm{h}$, other section shown in Fig. 5) where rigid-body-mode carbody vibrations were particularly marked. An acceleration PSD peak due to rigid-body-mode vibrations was observed at approximately $1.4 \mathrm{~Hz}$ both directly above the rear bogie centre (Fig. 6(a)) and in the centre of the carbody (Fig. 6(b)).

By applying the sky-hook control ("Sky-hook (RBM)" in Fig. 6), vibrations with a frequency of around $1.4 \mathrm{~Hz}$ were slightly suppressed compared to cases "without control". In contrast, when the LQG control ("LQG (RBM)"in Fig. 6) was applied, the PSD peak 
around $1.4 \mathrm{~Hz}$ was reduced by approximately half, both on the floor above the rear bogie centre and in the carbody centre, however the PSD at $3 \mathrm{~Hz}$ or above, increased slightly.

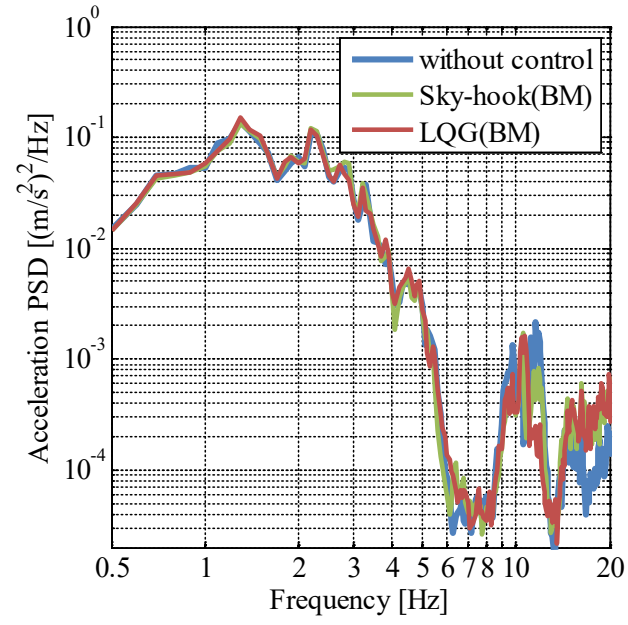

(a)

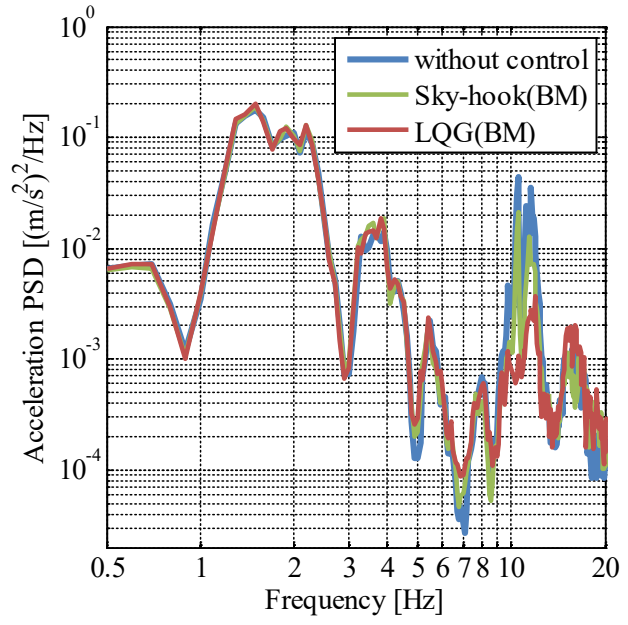

(b)

Figure 5: Vertical acceleration PSD of the carbody floor in vehicle running tests where bending-mode carbody vibrations were particularly marked (running speed $=$ $100 \mathrm{~km} / \mathrm{h}$ ). (a) On the floor above the rear bogie centre; (b) On the floor in the carbody centre.
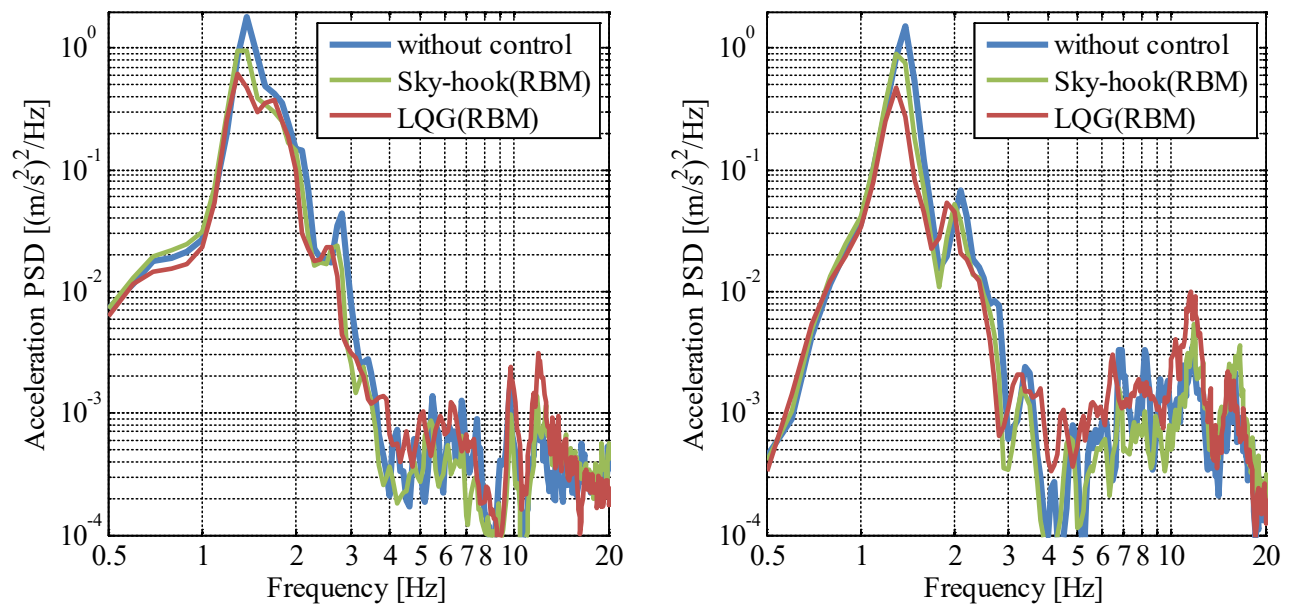

Figure 6: Vertical acceleration PSD of the carbody floor in the vehicle running test (running speed $=60 \mathrm{~km} / \mathrm{h}$ ). (a) On the floor above the rear bogie centre; (b) On the floor in the carbody centre. 


\section{CONCLUSION}

This paper reported on the results of vehicle running tests applying a primary suspension damping control system. The tests were carried out on secondary line with relatively low running speeds for the first time, rather than on main lines, such as Shinkansen lines. The following findings were obtained in the running tests:

a) The system reduces vertical bending mode carbody vibrations even on secondary lines.

b) The system reduces vertical rigid-body-mode carbody vibrations by using an LQG controller adjusted to reduce rigid-body-mode vibrations.

These results indicate that the gain-scheduling control technique based on vertical carbody vibrations achieves a better vibration suppression performance. Furthermore, simultaneous usage of the system and the secondary suspension damping control system [13] seems to be effective even when a vehicle is running on a secondary line.

\section{ACKNOWLEDGEMENT}

Particular thanks are expressed to the relevant personnel at the Kyushu Railway Company, who provided valuable assistance and made it possible to carry out the vehicle running tests.

\section{REFERENCES}

[1] Bruni, S., Goodall, R.M., Mei, T.X. \& Tsunashima, H., Control and monitoring for railway vehicle dynamics. Vehicle System Dynamics, 45(7)-(8), pp.743-779, 2007.

[2] Ueno, M, Usui, S., Tanaka, H. \& Watanabe, A., Technological overview of the next generation Shinkansen high-speed train Series N700. Proceedings of the 8th World Congress on Railway Research (WCRR2008), Session R.1.3.3, 2008.

[3] Goto, O., Negoro, S. \& Koizumi, S., The development of an active suspension system with EMA for railway vehicles. Proceedings of the International Symposium on Speed-up Safety and Service Technology for Railway and Maglev Systems 2009 (STECH'09), 2009.

[4] Sugahara, Y. et al., Practical use of a vehicle vibration control system using secondary variable vertical dampers on a sightseeing train. Proceedings of the First International Conference on Railway Technology: Research, Development and Maintenance (Railways 2012), Paper No. 31, 2012.

[5] Sugahara, Y., Kojima, T., Akami, Y. \& Igarashi, Y., Development of a vertical semiactive suspension system using variable hydraulic dampers. Proceedings of the 15th International Conference on Railway Engineering Design and Operation (Comprail 2016), pp. 469-477, 2016.

[6] Development of a vibration suppression system using variable hydraulic vertical dampers for railway vehicle, The Japan Society of Mechanical Engineers, JSME Medal for New Technology. https://www.jsme.or.jp/english/about/awards/2017-2/ award2017-nt2/. Accessed on: 27 Apr. 2018.

[7] Sugahara, Y., Takigami, T. \& Koganei, R., Suppression of vertical bending vibration in railway car bodies by primary suspension damping control (Results of running test using Shinkansen vehicle). Proceedings of the 21st International Symposium on Dynamics of Vehicles on Roads and Tracks (IAVSD09), Paper No. 13, 2009.

[8] Sugahara, Y., Kazato., A., Koganei, R., Sampei, M. \& Nakaura, S., Suppression of vertical bending and rigid-body-mode vibration in railway vehicle car body by primary and secondary suspension control (Results of simulations and running tests using Shinkansen vehicle). Proceedings of the Institution of Mechanical Engineers, Part F, Journal of Rail and Rapid Transit, 223(6), pp. 517-531, 2009. 
[9] Sugahara, Y., Watanabe, N., Takigami, T. \& Koganei, R., Vertical vibration suppression system for railway vehicles based on primary suspension damping control-system development and vehicle running test results. Proceedings of the 9th World Congress on Railway Research (WCRR2011), Session-D2, 2011.

[10] Karnopp, D. Crosby, M.J. \& Harwood, R.A., Vibration control using semi-active force generators. Transactions of the American Society of Mechanical Engineers, Journal of Engineering for Industry, Ser. B, 96(2), pp. 619-626, 1974.

[11] Anderson, B.D.O. \& Moore, J.B., Linear Optimal Control, Prentice-Hall, 1971.

[12] Suzuki, H., Research trends on riding comfort evaluation in Japan. Proceedings of the Institution of Mechanical Engineers, Part F, Journal of Rail and Rapid Transit, 212(1), pp. 61-72, 1998.

[13] Sugahara, Y., Kojima, T., Sannomiya, D., \& Miyahara, K., Suppression of vertical vibrations in railway vehicles using variable primary and secondary hydraulic dampers. The First International Railway Symposium Aachen (IRSA 2017), 2017. 